\title{
Nano- and Microporosity in Geopolymer Gels
}

\author{
J. L. Bell, M. Gordon and W. M. Kriven \\ Department of Materials Science and Engineering, University of Illinois at Urbana Champaign, \\ Urbana, IL 61801
}

Geopolymers and geopolymeric composites are a relatively new class of ceramic materials whose intrinsic properties and potential applications are still relatively under-explored. ${ }^{1}$ Pure geopolymers are rigid, inorganic, aluminosilicate, hydrated gels, charge balanced by the presence of Group I cations such as $\mathrm{Na}^{+1}, \mathrm{~K}^{+1}, \mathrm{Cs}^{+1}$. They have a range of compositions, but a nominal composition of interest here is around $\mathrm{Al}_{2} \mathrm{O}_{3} \bullet \mathrm{M}_{2} \mathrm{O} \bullet \mathrm{nSiO}_{2} \bullet 10 \mathrm{H}_{2} \mathrm{O}$, where $\mathrm{M}=\mathrm{Na}, \mathrm{K}$, or Cs, and $\mathrm{n}$ varies from 2-4. ${ }^{2,3}$ Geopolymers are totally inorganic, and usually made by mixing a powder with a solution, forming a paste which is poured into a plastic mold or adhered on a metal, glass or ceramic surface. The mixture is allowed to set for $24 \mathrm{~h}$ at ambient temperatures (e.g. $40{ }^{\circ} \mathrm{C}$ ) and pressures. They do not adhere to polymers or graphite, so that a variety of complex shapes of near net dimensions can be fabricated. Geopolymers are acid resistant and thermal shock resistant.

The intrinsic microstructure is nanoparticulate ( $\leq 5 \mathrm{~nm}$ in size) and nanoporous as seen in STEM (Fig. 1). Since the MIP technique was not responsive below $10 \mathrm{~nm}$ pore sizes, the nanoporosity was investigated by BET surface area analysis. The technique is able to measure surface areas and pore sizes down to below $0.2 \mathrm{~nm}$. When made from natural metakaolin, geopolymers have an average pore radius of $\sim 3.4 \mathrm{~nm}$, and the porosity constitutes $\sim 40 \%$ by volume of the material (Fig. 2). When the geopolymer is made from a pure, synthetic alumino-silicate metakaolin in which the $\mathrm{Al}$ atom is in five-fold co-ordination, the average pore radius decreases to $\sim 0.8 \mathrm{~nm}$, and the pores again constitute $\sim 40 \%$ of the volume. The porosity can be varied by selection of $\mathrm{Na}^{+}$or $\mathrm{K}^{+}$charge-balancing cation, where the latter produces a relatively homogeneous dispersion of fine, micron sized pores distributed in the nanoporous body. The porosity can be modified and enhanced by additions of $\mathrm{Al}$, or by using hydrogen peroxide $\left(\mathrm{H}_{2} \mathrm{O}_{2}\right)$ in the alkali metasilicate reaction solution. Fig. 3 illustrates preliminary work on producing bi-modal porosity by using hydrogen peroxide solution in a pressure vessel. The mesoporosity superimposed on the nanoporosity is of the order of $50 \mathrm{~mm}$ in diameter. To achieve smaller pore sizes, higher pressures are needed.

\section{References}

[1] J. Davidovits, Journal of Thermal Analysis, 35(2) (1989) 429.

[2] "Microstructure of Geopolymers and Geopolymer-based Materials," W. M. Kriven, J. Bell, M. Gordon and Gianguo Wen, pp 179-183 in Geopolymer, Green Chemistry and Sustainable Development Solutions, edited by Joseph Davidovits. Proc. World Congress Geopolymer,2005, St. Quentin, France.

[5] This research was supported by the Air Force Office of Scientific Research Contract\# FA9550-04-C-0063. The help from Dr. J. G. Wen is gratefully acknowledged. Microscopy analysis was conducted at the Center for Microanalysis of Materials, University of Illinois, which is partially supported by the U.S. Department of Energy under grant DEFG02-91ER45439. 

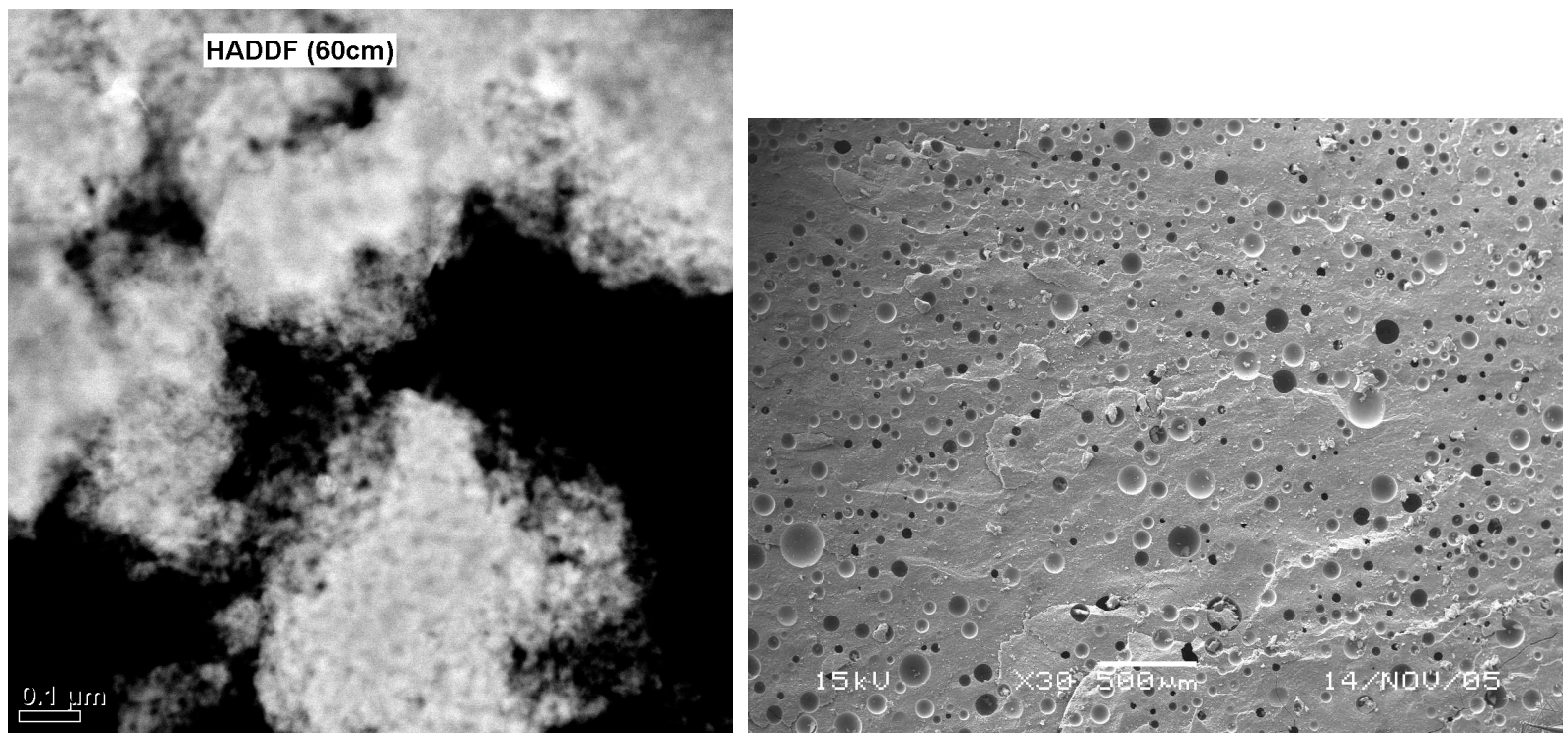

Fig. 1. STEM micrograph of crushed, Na-based Fig. 3. SEM micrograph of fracture surface of geopolymer showing its nanoparticulate and geopolymer synthesized using hydrogen and nanoporous nature. peroxide $\left(\mathrm{H}_{2} \mathrm{O}_{2}\right)$ in a sealed container at $\sim 3.5$ $\mathrm{M} \mathrm{Pa}$ of pressure and 50C.

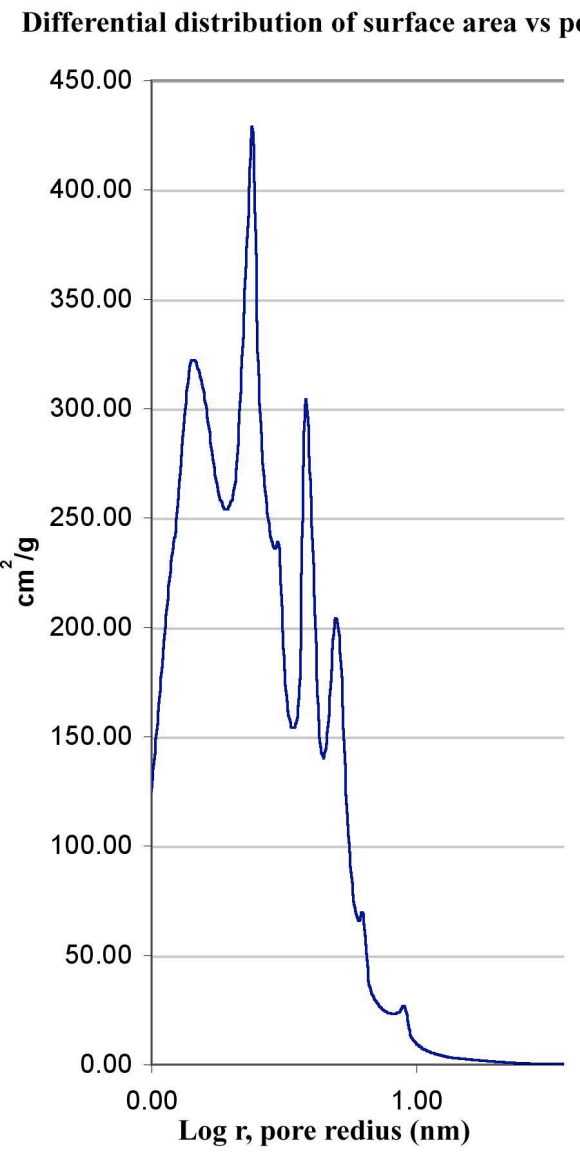

Fig. 2. Differential distribution of surface area versus pore radius showing a multimodal distribution 